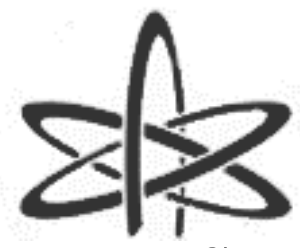

BJRS
BRAZILIAN JOURNAL

$\mathrm{OF}$

RADIATION SCIENCES

08-03A (2020) 01-19

\title{
The future of nuclear energy and maritime power
}

\section{relations}

\author{
Claudio Rodrigues Corrêa, Taíssi Pepe de Medeiros, Gustavo André Guimarães \\ Simulations and Scenarios Lab - Brazilian Naval War College \\ correa7claudio@gmail.com
}

\begin{abstract}
Considering the presence of the nuclear issue in the main international forum and agenda as well as the increase in the visibility of the Brazilian Navy's Strategic Projects in the nuclear area, it is necessary to discuss the long-term aspects of this sector of capital importance for Brazil, which is likely to shape the country's development path in the next decades. This paper aims to use scenarios to propose a reflection on future environments concerning nuclear energy in which organs and sectors of Brazilian society (including Brazilian Navy) will act primarily in areas that have direct or indirect implications for maritime power and its interconnections with national development and international relations. This proposal includes discussing the prospective methods that will allow the reflection on the benefits of nuclear technology for Brazil and the international community, the technological challenges that are still facing for its effective implementation, and the possible revisions or redefinitions of formats for non-proliferation agreements. Issues to be addressed include the expansion of the uses of nuclear power and benefits can it provide to the future international community and to the maritime power; the changes that may occur in non-proliferation agreements. In environments of uncertainty and complexities, such as the nuclear area, prospective scenarios methodology stimulates the interaction among the different involved parts, with its cultural, economic and social vision, taking part in defining the possible scenarios. Planners and leaders can gain exceptional ability to anticipate the actions that can drive the real world and produce precious insights.
\end{abstract}

Keywords: nuclear energy, maritime power, prospective methods, future scenarios. 


\section{INTRODUCTION}

Energy drives the engines of industrial and food production, transportation, building construction, space heating, transformation of landscapes, recreation, etc. Abundant energy enables higher and more efficient utilization of resources [1].

The Brazilian National Defense Strategy states at the beginning of the document that the growing international insertion of the country must be accompanied by the preparation of its defense against threats and aggressions. The same document also affirms the South Atlantic and the Amazon as priority areas for the National Defense and also the country must strength three areas of strategic importance: space, cybernetic and nuclear [2].

Brazil has a commitment - due to the Constitution and adherence to International Treaties - with the strictly peaceful use of nuclear energy. However, it affirms the strategic need to develop and master this technology. Brazil needs to ensure the balance and versatility of its energy matrix and move forward in areas such as agriculture and health that can benefit from nuclear energy technology [2].

There were analysis developments and predictions of the politically controversial idea that nuclear fission power would be the dominant energy resource of the 21 st century. The superabundance of nuclear power would feed the world, supply its drinking water, and raise the per capita income and standard of living without creation of polluting greenhouse gases if the humankind could achieve unprecedented world cooperation, but some studies point that we're losing the fight against nuclear proliferation $[1,3]$.

Technological safety, nuclear waste, costs and the individual energy policies of Member States are some of the problems and perceptions about the future of nuclear energy in Europe. It was also asked, among other questions, if nuclear power is viable as a clean and independent energy source. With the evolution of new science and technology, the positive contribution of nuclear energy to sustainable development should be weighed in the balance [4]. 
When considering the contributions of the nuclear energy to Conflict Management, Peace Economics and Development, one has to know that a nuclear future cannot be outlined in isolation from general trends of world development and that globalization has engaged the countries in an interconnected economy and integrated society [5].

The complexity of the global threats and opportunities in the nuclear power environment leads to the conclusion that cooperative actions are the best measures to deal with issues of common interest. In this context, it is of great value the use of instruments that provide interaction and joint production of knowledge necessary for strategic planning and decision-making also in the field of international relations. Therefore, it is worth highlighting the usefulness of the prospective scenarios construction methodology to the concrete case.

In essence, scenarios may be defined as a set of tools that provides a diversified vision of certain actions possible outcomes. Thus, besides challenging the common sense, scenarios may help to avoid undesirable results, since different strategies are drawn from different possible events, which aid the decision-making process of policymakers $[6,7]$.

Far from being a predictive method, they are a carefully organized set of tools, highlighting the causal relationships of the most significant elements of the environment (such as actors, forces, and logics) to order perceptions about future alternative environments so that the decision-making process of policy makers and other decisionmakers (not only, but also), in the field of international relations and political science, can be expanded $[8,9]$.

From the above, this article aims to propose a methodological arrangement of tools of prospective scenarios to support cooperative talks among the representative actors of the nuclear industry in order to strengthen their joint decisions on the future.

This paper is divided into four sections. The first intends to present the strategic importance of the nuclear energy to world level, highlighting the long range perspective and the necessity of methodological tools to look beyond the horizons. The second seeks 
to identify the prospective scenarios among other studies methodologies to examine future environments. The following section raises and examines issues of nuclear sector in question, ranging from the nuclear agenda, the Brazilian nuclear projects, nuclear power, military uses of nuclear technology to some possibly disruptive nuclear technologies. It aims to indicate the existing key long-term issues to build a cooperative environment necessary to handle nuclear issues. Finally, the fourth section elucidates the main topic of this paper. A sequence of methodological tools of scenarios planning are set to help in the decision-making processes, in the construction of medium and longterm strategic planning, and to increase the interchange among the participating agents to deal with threats and adversities always in order to strengthening peace, coordination and cooperation among the stake holder of the nuclear energy sector.

\section{FUTURE METHODOLOGIES FOR THE STUDY OF ENVIRONMENTS}

The prospective scenarios, part of a larger set of methods of future studies, were pioneering used in the war games and in the Shell Oil Company. Since then, states and companies have used it for decades. By their use, decision makers can have a diversified view of results, such as an action that can be theirs or of their agents, as well as the options for action in the estimated circumstances. This method is, above all, a qualitative approach to structure the information and open the mental models of those who wish thinking in a long term, without ruling out the historical process $[10,11]$.

\footnotetext{
Scenario approach, when used appropriately, may significantly mitigate risk exposure of the company. Conclusions which have been made on selected industrial companies can be extended to other industrial branches. Practical application of scenario planning method confirmed that this approach was superior to deterministic single scenario model. Scenario technique thus compensates for deficiencies and omissions which are inherent in simplistic deterministic model [12].
}

Introducing systematically the scenario methodology on the International Relations (IR) field, Han [7] argues that this is one of the most effective methods to connect the theory to the practice, leading to a better understanding of future world events once that it is based on critical information of how the identified policy makers behave and how 
influential these ones are, in terms of changes and shaping outcomes of problems solving in a real world.

Scenarios can and should be used for near-term business decisionmaking. Scenarios need to be applied to the numerous operational issues that companies face. As such, they are a key method of analysis, especially for highly uncertain circumstances [13].

Considering the existence of more than one possible future, it is intended to enlarge mental maps to make the most robust strategic decisions for the greatest range of future scenarios and to be able of, as from the knowledge and monitoring of the critical factors that will form them, to avoid threats and get the most out of the opportunities $[8,9]$.

Experts from several fields used their insight to apprehend an energy future and depicted, from scientific and technological perspectives, a vision of a different future society from the one that would emerge in a traditional linear scenario in which a proper balance is struck between the usage of S\&T and its limitations [14].

At the defense and security arena, it is also useful to expand awareness and preparation for the occurrences of events considered somehow unpredictable, such as Black Swans, Pink Flamingos and Dragon Kings [15]: Black Swans are high impact unpredictable events that can be retrospectively explained [16]; Pink Flamingos are foreseeable events that were ignored by cognitive bias problems of leaders involved by powerful institutional forces [17]; and Dragon Kings are extreme events leading to instability and rupture, that can be recognized and predictable by early warning signals that were neglected due to its slow development [18].

All of these events tend to be ignored by the confirmation bias, whereby the human mind seeks to confirm its assumptions and theories by observing the facts that reinforce them, ignoring those who contradict them, inducing the collective error of decision makers strategic blindness, who pass to misread the weak signs of development or change in trends and then are surprised by changes that were supposed to be unpredictable.

Corrêa and Flor [19] and Corrêa and Cagnin [20] already suggest prospective scenarios together with the war games aiming to promote cooperation and interaction 
among actors at the strategic political level and the maintenance of peace in the South Atlantic once that, among other benefits, they improve the culture of cooperation between civilians and military within each State and among them through the sharing of information and practices of common interest.

Popper [10] researched the fundamental attributes of foresight methods and their links to the main phases of multi-factorial prospecting processes, which may be of qualitative, quantitative or semi-quantitative nature. Capacity, its potential to collect or process information, can be based on evidence, expertise, interaction or creativity:

- Evidence - Explanation of phenomena with the support of reliable documentation and through analysis of statistics and various types of measurement indicators;

- Expertise - Tacit skills and knowledge of individuals in a given area, with privileged access to relevant information or accumulated knowledge from several years of experience.

- Interaction - Challenged experience on articulate with other knowledge from other non-specialist stakeholder views through participatory processes.

- Creativity - A mixture of original thinking and imaginative ability that emerges from groups of people (including artists or tech gurus) involved in brainstorming sessions for example.

Futures study methods are borrowed and adapted from those used in other disciplines such as management, planning and social sciences. Their uniqueness lie in the combination of futures thinking, networking and policymaking [10].

Depending on availability of resources to one particular prospective study, as experts, time and data, each situation requires a specific arrangement of foresight methods in order to gather and understand the key variables and its causal relationships $[10,11,13]$.

One of the most used sequence of methods to collect, process, debate and prioritize information about the future and build scenarios is the one that uses tools as Environmental Scanning, Delphi Method, Cross Impact and Structural Analysis to define 
a small number of key-factors, select the two drivers of the highest importance and the greatest uncertainty to the future environment and use them as pairs of axes creating a $2 \times 2$ matrix which forms the basis for possible scenarios. Each of them will describe the development of those key-factors considering their consistency and robustness within a range of environments, based on group diversity and flexibility. It is also practiced by many consulting company, being "Global Business Network" one of them $[6,12,14]$.

\section{NUCLEAR ISSUES}

\subsection{Nuclear Agenda}

Since 1938, when Lise Meitner identified the nuclear fission process, uranium received special attention as a controversial chemical element. In 1941, Glenn T. Seaborg artificially produced plutonium from uranium [21]. Finally, the first three nuclear explosions (Trinity Test, Hiroshima and Nagasaki, all of them in 1945) took place in our planet and created an apparently insoluble problem of long-range policy usually called nuclear proliferation:

\footnotetext{
If we can solve the difficult worldwide problems of nuclear proliferation, nuclear waste, and nuclear safety, uranium could play a positive role in our future. Within a system of nuclear reactors constructed to operate without risk of leakage of radioactive waste, the power of uranium could be harnessed to produce clean energy. Radioisotopes, nuclear fission's by-products, may continue to be useful in medicine, helping in diagnoses of disease and providing cures for cancer, both directly and through medical research. The end of the Cold War and the changes in the global economy place us at a crossroads. Now is the time to make the important decisions about uranium and its uses - decisions that can make a difference in the future of our planet [22].
}

In geopolitical terms, the double-faced role of uranium use (peacefully-military) still takes account. Just to give one extreme example, Iran's nuclear program is doomed to deal with deadlocks. On the other hand, many other countries also run into several difficulties when trying to obtain nuclear technology. Nevertheless, despite some drawbacks, a significant progress can be identified in Brazil regarding to Nuclear Fuel Cycle, Research Reactors, Nuclear Power Plants and Naval Nuclear Propulsion System [23]. 


\subsection{Brazilian Nuclear Projects}

In 2018, combined information from NEA, the Nuclear Energy Agency of OECD Organization for Economic Co-operation and Development, \& IAEA - International Atomic Energy Agency reported, Brazil reached the $8^{\text {th }}$ position in the ranking position for uranium resources, with the values as shown by Table 1[24]:

Table 1: Brazilian Resources of Uranium by type and costs range. (Uranium resources as of 1 January 2017, tonnes U, rounded to nearest 100 tonnes)

\begin{tabular}{|c|c|c|c|c|}
\hline NEA \& IAEA & \multicolumn{4}{|c|}{ Costs Range - recoverable at a cost of (less than $)^{\mathrm{a}}$} \\
\hline $\begin{array}{l}\text { Categories of } \\
\text { Resource }^{\mathrm{b}}\end{array}$ & $<\mathrm{USD} 40 / \mathrm{kgU}$ & $<\mathrm{USD} 80 / \mathrm{kgU}$ & $<$ USD 130/kgU & $<\mathrm{USD} 260 / \mathrm{kgU}$ \\
\hline Ident. res. recov. $^{\mathrm{c}}$ & 138100 & 229400 & 276800 & 276800 \\
\hline Ident. res. in situ & 184300 & 314600 & 382300 & 382300 \\
\hline RAR recoverable $^{\mathrm{d}}$ & 138100 & 155900 & 155900 & 155900 \\
\hline RAR in situ & 184300 & 209700 & 209700 & 209700 \\
\hline IR recoverable $\mathrm{e}^{\mathrm{e}}$ & 0 & 73500 & 120900 & 120900 \\
\hline IR in situ & 0 & 104900 & 172600 & 172600 \\
\hline
\end{tabular}

a. 1 short ton $\mathrm{U}_{3} \mathrm{O}_{8}=0.769 \mathrm{tU} ; 1 \% \mathrm{U}_{3} \mathrm{O}_{8}=0.848 \% \mathrm{U} ; 1 \mathrm{USD} / \mathrm{lb} \mathrm{U}_{3} \mathrm{O}_{8}=\mathrm{USD} 2.6 / \mathrm{kg} \mathrm{U} ; 1$ tonne $=1$ metric ton.

b. in situ - uranium expected to occur in deposits. It includes prognosticated resources (PR) and speculative resources (SR).

c. Identified resources $-\mathrm{RAR}+\mathrm{IR}$.

d. Reasonably assured resources (RAR) - uranium that occurs in known mineral deposits of delineated size, grade and configuration such that the quantities can be specified.

e. Inferred resources (IR) - uranium that is inferred to occur based on direct geological evidence or with data considered to be inadequate to classify the resource as RAR.

Brazilian Nuclear Industries - INB, a state-owned company subordinated to Brazilian Ministry of Mines and Energy, is responsible for the inner activities related to the Nuclear Fuel Cycle, which is a state monopoly as per Constitution. The company dominates the entire cycle of uranium enrichment through ultracentrifugation with the indigenous technological development. In this context, we should note the fact that the ultracentrifuge technology was fully developed by CTMSP (Brazilian Navy Technology Institute in the city of São Paulo). However, the economic feasibility of the entire process depends on the uranium domestic consumption to reach its break-even. For now, the company outsources the inefficient stages. 
The same source shows by Table 2 the gap between Brazilian recent uranium production and its current capacity from 2013 to 2016 [24]:

Table 2: Brazilian uranium production, current capacity and capacity utilization, 20132016, $\mathrm{tU}$

\begin{tabular}{|c|c|c|c|c|}
\hline & 2013 & 2014 & 2015 & 2016 \\
\hline Production & 198 & 231 & 38 & 44 \\
\hline Current Capacity & 340 & 340 & 340 & 340 \\
\hline Capacity Utilisation & $58 \%$ & $68 \%$ & $11 \%$ & $13 \%$ \\
\hline
\end{tabular}

Brazilian uranium mining and production are interconnected with domestic demand. Since Angra III nuclear power plant construction has a significant delay (1984mid2026?), it represents a severe bottleneck to further projects. Rio de Janeiro state has the only two operating nuclear power plants (Angra I and II - PWRs) which provide $2.5 \%$ of domestic energy supply and represents $1.6 \%$ of the installed capacity $(1,990$ MW) among other energy sources. Angra III is supposed to add 1,405 MW, which would increase the uranium consumption enough to allow INB operate at full capacity.

Recently, Brazilian government has unofficially ${ }^{1}$ announced the Itacuruba Project in the state of Pernambuco [25, 26]. There are plans to build up to six new units of nuclear power reactors. The Brazilian Multipurpose Reactor (RMB) designed to give selfsufficiency in pharmaceuticals radioisotopes and the Brazilian Navy Submarine Programme (PROSUB) can be included as outstanding ongoing projects.

\subsection{Nuclear Power}

At the end of 2018, 451 reactors were operable in several parts of the world and with 55 reactors under construction, as shown in Table 3 [27]:

Table 3: Type of operational reactors / under construction reactors, 31 DEC, 2018

\begin{tabular}{|c|c|c|c|c|c|c|c|c|}
\hline Reactors & PWR $^{\mathrm{a}}$ & BWR $^{\mathrm{b}}$ & GCR $^{\mathrm{c}}$ & PHWR $^{\mathrm{d}}$ & LWGR $^{\mathrm{e}}$ & FBR $^{\mathrm{f}}$ & HTGR $^{\mathrm{g}}$ & Total \\
\hline Operational & 298 & 73 & 14 & 49 & 14 & 3 & - & 451 \\
\hline
\end{tabular}

1 Reive Barros dos Santos, Secretary of Planning and Energy Development, Mines and Energy Ministry, World Spotlight Nuclear Brazil in April 3 ${ }^{\text {rd }}, 2019$ presentation (p. 21). 


\begin{tabular}{|c|c|c|c|c|c|c|c|c|}
\hline $\begin{array}{c}\text { Under } \\
\text { Construction }\end{array}$ & 45 & 4 & - & 4 & - & 1 & 1 & 55 \\
\hline
\end{tabular}

a. Pressurized Light-Water Moderated and Cooled Reactor.

b. Boiling Light-Water Cooled and Moderated Reactor

c. Gas Cooled, Graphite Moderated Reactor

d. Pressurized Heavy-Water Moderated and Cooled Reactor

e. Light-Water Cooled, Graphite Moderated Reactor

f. Fast Breeder Reactor

g. High Temperature Gas Cooled Reactor

All the designs above are under III / III+ nuclear power reactors generation. A set of improvements is available of course, but they cannot handle with the worldwide central challenges. Considering that nuclear remains a key element to decarbonizing electricity, some countries are now returning with new impulse to embrace nuclear energy. Global warming, nuclear waste and non-proliferation exigencies claim new generation of safer power plants designs [28].

To take in account these requirements, six fourth generation reactors concepts were chosen to a $R \& D$ race to achieve these urgent demands. Some of them operate with a thorium fuel cycle, a new paradigm under investigation. Some prototypes are expected to be built until 2030 [29].

\subsection{Military Uses of Nuclear Technology}

Besides nuclear bombs based in fission or fusion usually discussed, small modular reactors for nuclear propulsion associated with non-proliferation efforts operate in a large range of situations. Today's most important improvements focus in avoiding widespread nuclear developments. In this case:

The twenty-first century must be the age in which we make nuclear proliferation ancient history. Tools exist today for detecting even minute levels of radiation in the environment, and governments must come together to put a complete halt to the illegal trade in nuclear materials. Research must be 
undertaken to develop new ways to detect nuclear activity by rogue nations [31].

Regarding to rogue states, we must consider this as an arbitrary U.S. determination, not an international agreement. Another international injury is the use of depleted uranium during Persian Gulf War (1990-91), NATO military actions in BosniaHerzegovina (1995) and Kosovo (1999) and in the coalition actions in Iraq (2003). Depleted Uranium (DU) is an abundant and comparatively cheap by-product of enrichment of uranium with reduced levels of the $235-\mathrm{U}$ isotope. These controversial armor-penetrating munitions had played a role in a wide variety of applications (e.g., radiation shielding, compact counterweights, armor, kinetic energy weapons). [30]

\subsection{Some Possibly Disruptive Nuclear Technologies}

Nonstrategic nuclear weapons is a term that creates some uncertainty and can be associated with dual-capable aircraft, atomic demolition munitions, ground-launched cruise missiles, ground-launched ballistic missiles with ranges less than 5,500 kilometers, artillery, air-defense weapons, and nuclear depth bombs [31].

OFNP - Offshore Floating Nuclear Plants is a plant concept that can be entirely built within a floating platform in a shipyard, providing a huge economy of mass production. OFNP eliminates earthquakes and tsunamis as accident precursors and its ocean-based passive safety systems eliminate the loss of ultimate heat sink accident by design and can offer an interesting economy of scale, depending on the chosen generation capacity [32].

Nuclear Fusion Power and Artificial Intelligence are both disruptive technologies. Nuclear Fusion Technology attracts through its energy potential as solar explosions. Simultaneously, deep learning is a new area inside of machine learning, a subject of artificial intelligence. Here, scientists try to build sophisticated algorithms for forecasting disruptions in nuclear plasma experiments. These combination of technologies increases expectations of a deep paradigm shift in nuclear technologies [33, 34].

\subsection{Key long-term issues}


Nuclear energy has been studied for its important role in the global energy supply, with outcomes on reducing carbon emissions, among others. However, the perception of Brazilian society is still incipient about the multiple uses and benefits derived from it. It should be noted that Brazil has the sixth largest uranium stockpile in the world.

Nuclear energy is considered a base energy, due to its non-intermittent capacity and high energy load, such as thermoelectric and hydroelectric. It has several beneficial applications in study and development in the field of medicine, environment, agriculture, research, etc. With respect to the Maritime Power, a submarine with nuclear propulsion has better conditions of maneuverability, an increase of speed and concealment of location, when compared to the conventional one.

However, there are technological challenges that must be overcome for effective implementation. According to Silva [35], such challenges can be defined in four areas: a) sustainability; b) competitiveness; c) safety and reliability; d) resistance to proliferation and physical protection.

Sustainability refers to issues of decommissioning nuclear plants and managing nuclear waste. Extending nuclear energy uses will require multiple facilities for storage. The pace of planning, licensing and construction of these facilities does not keep up with the growth of nuclear energy uses on a global scale. This challenge is notorious, for it runs up against the existence of future generations and of the environment.

With respect to competitiveness, nuclear plant projects are costly in addition to the costs of decommissioning, which are part of the life cycle of a nuclear plant. Projects will need to be more economical and ingenious. Safety and reliability in relation to nuclear power were put in check due to nuclear accidents. Public acceptance can only be improved as knowledge about the benefits of nuclear energy is propagated and the safety of nuclear assets is maximized. 
Regarding resistance to proliferation and physical protection, with the increasing industrialization of countries, control of nuclear technologies becomes more complex [36], while the future comes through the expansion of nuclear energy in the world. This poses challenges to the IAEA, which is the guardian for compliance with the NPT - NonProliferation Treaty. This demands more sophisticated systems and tighter controls for the protection of nuclear material. Nuclear technologies are targeted by state and nonstate actors, as well as by terrorist groups. The IAEA's efforts to strengthen safeguards mechanisms increasingly require active participation and coordination of States.

There are also technical barriers in the verification that are faced by the IAEA that compromise the guarantee of non-proliferation. An inspection may arrive too late and not find any more traces.

This study foresees the possibility for revisions or redefinitions of the formats for nonproliferation agreements concluded by the IAEA as nuclear technologies dynamically change over time and there will be an expansion in applications with a declared peaceful purpose. An international storage bank for used fuels is even discussed.

\section{A PROPOSAL TO STUDY NUCLEAR ENERGY ENVIRONMENTS}

\subsection{Methodological Arrangement}

This proposed process of building forward-looking scenarios for the Brazilian nuclear sectors consists of an arrangement of prospective tools used to understand the past behavior and estimate possible developments of the most important uncertainties, as mentioned here in section one. This arrangement is displayed here in the following actions (grouped in stages) to be carried out by a control group (CG, it is suggested to be composed by five members) of the Brazilian nuclear community. They will be responsible for promoting the collection, exchange and dissemination of data and information, transforming them into knowledge about the future. 
It can be made by consultations with the research centers, national ministries, business representatives, branch associations and other interested stakeholders, their academic, diplomatic, industrial, commercial, social and cultural communities, as well as reliable sources, primarily those linked to the nuclear sector, outside the country $[6,7,10,20]$ :

1 - To improve existing knowledge and share it among community members in order to generate mutual trust, expansion of mental models and depth of information: Literature Review Workshops and Benchmarking in documents, articles and databases of neighboring countries and of other countries about the relevant issues and trends of impact in the future of the nuclear sector. The main product of this stage is a set of dozens important factors to the Brazilian sector future.

2- To gather tacit knowledge: qualitative researches and open interviews; brainstorming sessions with members (politicians, leaders of social and cultural movements, academics, diplomats, military, entrepreneurs for example) from various groups from different countries; consultations with specialists in the specific areas of knowledge with direct or indirect impact on the nuclear sector by the use of Delphi method of consultation. From this stage, the main product is a list of (approximately) twenty key-factors for the formation of possible futures.

3 - To create new knowledge and expand the existing ones: selection and prioritization of key factors by cross-impact method and matrix of motricity and dependence; and confirmations and generation of consensus by Delphi method, through specific specialists on nuclear energy. From this stage, a list of five prioritized critical uncertainties emerges.

4- The first two critical uncertainties will be used as axes to assemble a matrix where its states of maximum and minimum occurrence form the orientation poles for the scenarios and, by the morphological analysis method, all five uncertainties are considered for consistency and robustness, to describe the four scenarios.

5 - These scenarios will be written in a shared form by representatives of these groups, condensed by the GC and presented in workshops to decision makers of the nuclear energy field. In them, they will map the opportunities and threats considered by brainstorming, as well as they will discuss the strategic decisions and actions of medium and long-term to take advantage and mitigate them respectively. 
Considering the strategy concept as something polysemic and, in a global way, as a set of decisions taken in the present viewing to achieve favorable results to decision makers and knowing the set of uncertainties and complexities related of the nuclear energy area, the use of scenarios can cooperate to build a greater national exchange of knowledge, facilitating common interests and presenting an integrated perspective for this sector.

\section{2 - Respondents and Sources of Research}

The challenges presented are relevant as long-term elements for a proposal to study the environments related to nuclear energy in Brazil and in the world. Among the issues that must be submitted to the respondents, the following should be considered:

I. The uses of nuclear energy will be expanded in the future and what benefits can nuclear energy provide to the future international community?

II. What are the challenges of nuclear technology for the future, will there be greater development and challenges will be overcome?

III. Will military uses be expanded and what are the impacts of their uses on the maritime power of States?

IV. What changes can occur in non-proliferation agreements, that is, how can nonproliferation agreements be shaped?

Respondents should not belong to a single area of knowledge or to a single institution. The different points of view tend to enrich the research. The questions above pervade Science \& Technology, Political Science, (Maritime Power) and Law, leastwise. For a concise study, one must observe the representativeness of these areas of knowledge, seeking a balanced distribution of the number of respondents. A consensus of opinions will not necessarily be obtained after the answers are collected. A synthesis of judgments is sought. The divergences in the responses should be carefully analysed, as they may 
signal some critical factor that is important and require a review to the study's control group.

It is pertinent to select respondents who are actors that compose the audience of interest of a study in this scope, so that they feel part of the exercise of thinking in the long term the subject matter in which they are inserted. In this case, the following actors are suggested: the scientific community; Armed Forces, including the (General Directorate of Nuclear and Technological Development of the Navy - DGDNTM); institutions and companies such as (CNEN, Eletronuclear, INB, AMAZUL); and; associations that cover the nuclear issue.

Research sources are extensive, but should be focused in the World Nuclear University, which produces numerous reports and future projections on nuclear energy, the (IAEA) itself, the nuclear technology reference centres and the international strategic documents of the armed forces which concerns the nuclear sector. These sources carry important elements for a study of the environments related to nuclear energy in Brazil and in the world.

\section{CONCLUSION}

The dynamism and complexity which the geopolitical and technological environments advance and the impact they exert on the national states require a great capacity of anticipation, learning and speed of decision, since interdependent events occur in Circumstances increasingly distant from the relationship of cause and effect, affecting distant actors among themselves in an oblique and non-linear way [36].

In environments of uncertainty and considerable complexities, such as the nuclear area, the use of this methodology stimulates the interaction among the different involved parts, each one having its own cultural, economic and social vision, and taking part in defining the possible scenarios. Thus, we can say that scenarios are effective to promote regional exchanges, support the reaching of common goals, and present an integrated perspective of a shared area. 
The scenario-based planning work should be able to account for the web of belief systems that shape the ways that future conditions and trends are created and acted upon. Planners and leaders can gain exceptional ability to anticipate the actions that can drive the real world toward one scenario or another and produce potent insights when they understand the scenarios narratives. Those are the people's beliefs, attitudes, perceptions, stories, images, about the future that provide the emotional context by which individuals and groups evaluate and internalize trends and other forces of that environment [37].

\section{REFERENCES}

[1] SCHAFFER, M. B; JUNCOSA, M. L. (1999). Our nuclear future: an era of clean energy abundance. Foresight, Vol. 1 Issue: 3, pp. 217-228. Available at: $<$ https://doi.org/10.1108/14636689910802151>. Last accessed: 26 Jun. 2019.

[2] BRASIL. Ministério da Defesa. Estratégia Nacional de Defesa. Brasília, DF. 2012. Available at: $<$ https://www.defesa.gov.br/arquivos/2012/mes07/end.pdf $>$. Last accessed: 26 Jul. 2018.

[3] INTRILIGATOR, M. D. (2011). We're Losing the Fight against Nuclear Proliferation, In: Manas Chatterji, Chen Bo, Rameshwar Misra (ed.) Frontiers of Peace Economics and Peace Science (Contributions to Conflict Management, Peace Economics and Development, Volume 16) Emerald Group Publishing Limited, pp.169 - 178

[4] RYLAND, D. (2002) -"The future of nuclear energy in Europe: questions, problems and perceptions", Managerial Law, Vol. 44 Issue: 4, pp.91-111. Available at: < https://doi.org/10.1108/03090550210770579>. Last accessed: 20 Jun. 2019.

[5] FEDOROV,Y. E. (2005), 11. Nuclear Dilemmas In The 21st Century, in M.D. Intriligator, A.I. Nikitin, M. Tehranian (ed.) Eurasia (Contributions to Conflict Management, Peace Economics and Development, Volume 1) Emerald Group Publishing Limited, pp. $111-121$.

[6] GODET M., Manuel de prospective stratégique, Dunod, Paris, 2001.

[7] HAN, Dong-ho. Scenario construction and its implications for international relations research. The Korean Journal of International Studies, v. 9, n. 1, p. 39-65, 2011.

[8] SCHWARTZ, Peter. A Arte da Visão de Longo Prazo. 4ed. Rio de Janeiro, 2006.

[9] JORDAN, Javier. Political and social trends in the future of global security. A metastudy on official perspectives in Europe and North America. European Journal of Futures Research (2017) 5:11. Available at: $<$ https://doi.org/10.1007/s40309-017-0120$\underline{\mathrm{x}}>$. Last accessed: 26 Jan. 2020.

[10] POPPER, Rafael. How are foresight methods selected? Foresight, v. 10, n. 6, p. $62-$ 89, 2008. 
[11] ROXBURGH, Charles. Strategy Practice - The use and abuse of scenarios. Mckinsey Quartely. November 2009.

[12] FOTR, J.; ŠPAČEK, M.; SOUČEK, I.; VACÍK, E. (2015) Scenarios, their concept, elaboration and application. Baltic Journal of Management, Vol. 10 Issue: 1, pp.73-97. Available at: $<$ https://doi.org/10.1108/BJM-01-2014-0004> . Last accessed: 16 Sep. 2019.

[13] MILLETT, Stephen M. (2003) The future of scenarios: challenges and opportunities. Strategy \& Leadership, Vol. 31 Issue: 2, pp.16-24. Available at: $<$ https://doi.org/10.1108/10878570310698089> Last accessed: 16 Jan. 2020.

[14] TAKAHASHI, R.; NAKAMURA, R.; WASHIDA, Y.; (2019). Socio-technological scenarios of Japan's future energy issues in 2050 based on scanning-based foresight method, Foresight. Available at: $<$ https://doi.org/10.1108/FS-12-2018-0115> Last accessed: 18 Jan. 2020.

[15] FARIA, M. M.; CORRÊA, C. R. . Cisne Negro e Flamingo Cor-de-Rosa implicações em planejamento estratégico de Defesa e Segurança. In: IX ENABEDEncontro Nacional da Associação Brasileira de Estudos de Defesa, 2016, Florianópolis-SC. Anais ... Florianópolis: ABED, 2016. v. 1. p. 1-500.

[16] TALEB, Nassim Nicholas. A Lógica do Cisne Negro. Rio de Janeiro: Best Seller, 2008.

[17] HOFFMAN, Frank. Black swans and pink flamingos: five principles for force design. War on the rocks. 2015. Available at:< http://warontherocks.com/2015/08/blackswans-and-pinkflamingos-five-principles-for-force-design $\geq$ Last accessed: 18 Nov. 2019.

[18] SORNETTE, Didier. Dragon-Kings, Black Swans and the Prediction of Crises. International Journal of Terraspace Science and Engineering. 2009. Available at: < https://arxiv.org/ftp/arxiv/papers/0907/0907.4290.pdf > Last accessed: 05 Jun. 2019.

[19] CORRÊA, C. R.; Flôr, C. R. de A. . Jogos de Guerra - Instrumentos para a Paz. Revista da Escola de Guerra Naval (Ed. português), v. 20, p. 126-137, 2013.

[20] CORRÊA, C. R; GAGNIN, C. H. Prospective games for defense strategic decisions in Brasil. Foresight. Vol. 18, $\mathrm{n}^{\circ} 1,2016 . \quad \mathrm{Pp} .4-23$. Available at: $<$ https://doi.org/10.1108/FS-07-2014-0047> Last accessed: 05 Jun. 2019.

[21] L'ANNUNZIATA, Michael F. Radioactivity: Introduction and History, From the Quantum to Quarks. Elsevier, Amsterdam, Netherlands (2016).

[22] ACZEL, AMIR D. Uranium wars: the scientific rivalry that created the nuclear age, Palgrave Macmillan, NY, USA (2009).

[23] ZOELLNER, TOM. Uranium: war, energy, and the rock that shaped the world, Viking Penguin, NY, USA (2009).

[24] Uranium 2018: Resources, Production and Demand. (2018). Available at: $<$ https://read.oecd-ilibrary.org/nuclear-energy/uranium-2018 uranium-2018en\#page159> . Last accessed: 05 Jun. 2019.

[25] World Nuclear Association, The Global Fuel Report: Global Scenarios for Demand and Supply Availability 2017-2035. World Nuclear Association, England (2017). 
[26] SANTOS, R. B., Política Energética - Energia Nuclear.Secretary of Planning and Energy Development, Mines and Energy Ministry, World Spotlight Nuclear Brazil in April $3^{\text {rd }}, 2019$ presentation (p. 21). Available at: $<$ https://www.eiseverywhere.com/file uploads/e3d641b69a38b13b6ee62ccaea7a2652 R eive Barros dos Santos Poltica Energtica.pdf>. Last accessed: 30 Jan. 2020.

[27] Nuclear Power Reactors in the World, (2019). Available at: $<$ https://wwwpub.iaea.org/MTCD/Publications/PDF/RDS-2-39 web.pdf $>$. Last accessed: 30 Jan. 2020.

[28] WORLD NUCLEAR ASSOCIATION, World Nuclear Performance Report 2018. World Nuclear Association, England (2018).

[29] Technology Roadmap Update for Generation IV Nuclear Energy Systems, (2014)., Available at: <https://www.gen-4.org/gif/upload/docs/application/pdf/201403/gif-tru2014.pdf $>$ Last accessed: 05 Jun. 2019.

[30] MILLER, A. C. (Ed.) Depleted uranium: properties, uses, and health consequences, CRC Press, Boca Raton, USA (2007).

[31] KRISTENSEN, H. M.; NORRIS, R. S., Nonstrategic nuclear weapons, Bulletin of the Atomic Scientists, 68(5), pp. 96-104 (2012).

[32] BUONGIORNO, J.; JUREWICZ, M. G..; TODREAS, N., The Offshore Floating Nuclear Plant Concept. Nuclear Technology, 194, pp. 1-14 (2016).

[33] KATES-HARBECK, J.; SVYATKOVSKIY, A.; TANG, W., Predicting disruptive instabilities in controlled fusion plasmas through deep learning, Nature, 4, (2019).

[34] WANI, M. A.; BHAT, F. A.; AFZAL, S.; KHAN, A. I., Advances in Deep Learning. Springer Nature, Singapore (2019)

[35] SILVA, A. T. O futuro da energia nuclear. Revista USP, São Paulo, n.76, p. 34-43, 2007-2008.

[36] WAYLAND, R. Strategic foresight in a changing world. Foresight. Vol. 17 iss: 5, pp. 444-459. 2015.

[37] KENNEY, S.H., PELLEY, B. A. (2014) Stories that drive the future: how narratives can improve scenario planning, Strategy \& Leadership, Vol. 42 Issue: 5, pp.28-33.

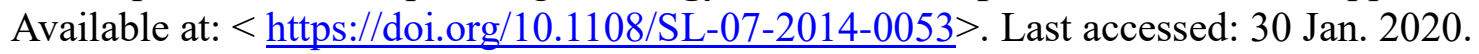

